\title{
What makes a bully a cyberbully? Unravelling the characteristics of cyberbullies across 25 European countries
}

\author{
Anke Görzig and Kjartan Ólafsson
}

Department of Media and Communications, London School of Economics and Political Science, London, UK; School of Humanities and Social Sciences, University of Akureyri, Akureyri, Iceland

Correspondence may be sent to Dr Anke Görzig, Department of Media and Communications, London School of Economics and Political Science, London WC2A 2AE, UK (email: A.S.Goerzig@lse.ac.uk)

Anke Görzig was the Survey Research Officer of the EU Kids Online II project at the Department of Media and Communications at the London School of Economics and Political Science. She is able to use her expertise as a quantitative researcher as well as in social policy research in managing and guiding the theoretically led data analyses of large-scale crossnational projects such as EU Kids Online II.

Kjartan Ólafsson is a lecturer at the University of Akureyri, Iceland, where he teaches research methods and quantitative data analysis. He was a member of the International Advisory Panel of the EU Kids Online project, and was active in designing the methodologies used. 


\title{
What makes a bully a cyberbully? Unravelling the characteristics of cyberbullies across 25 European countries
}

\author{
The characteristics of bullies who act face to face and those who do so in \\ cyberspace were compared directly in one sample across 25 countries. The nature \\ of cross-country differences due to their technological infrastructure was also \\ explored. Cyberbullies compared to face-to-face bullies were more likely to \\ engage in risky online activities, spend more time online, and were finding it \\ easier to be themselves online. Private access to the internet did not make a \\ difference. Gender differences showed girls more likely to be cyber- than face-to- \\ face bullies when a profile on a social networking site was present. Age and \\ internet ability beliefs were also positively but not independently associated with \\ cyberbullying. Cross-country differences were small and patterns remained \\ mostly stable across countries, suggesting that individual and not country-level \\ characteristics are pivotal in explaining cyberbullying.
}

Keywords: cyberbullying; bullying; internet; adolescence; aggression; online harassment; Europe; cross-country analysis

\section{Introduction}

The aim of this study is to identify which factors differentiate between children who use modern technological devices to bully others (i.e., cyberbullies) and those who bully others face-to-face. Despite the lack of consent in the definition of cyberbullying (cf. Slonje, Smith \& Frisen, in press) most researchers employ definitions similar to the one of traditional or face-to-face bullying, which is as an act of aggression that is intentional, repetitive, and towards an individual of lower power (cf. Olweus, 1993), but they extend it to electronic forms of contact (Perren, Dooley, Shaw, \& Cross, 2010; Smith et al., 2008). Cyberbullying can take various forms such as sending unwanted, derogatory, or threatening comments, spreading rumours, sending pictures or videos that are offensive or embarrassing by text, email, chat, or posting on websites including social networking sites (SNS) (e.g. Ybarra \& Mitchell, 2004a). 
A growing number of studies have suggested that bullying is a precursor for various health-related problems. Cross-sectional studies have shown that children who are bullied show a range of problems, including internalizing disorders (Hawker \& Boulton, 2000), externalizing disorders (Nansel, Overpeck, Haynie, Ruan \& Scheidt, 2003), social difficulties (Forero, McLellan, Rissel, \& Bauman, 1999), physical health problems (Kumpulainen, Räsänen, \& Henttonen, 1998), and suicide ideation (Kim, Koh, \& Leventhal, 2005). In addition, longitudinal studies have related bullying to both adjustment and health-related problems in adulthood (Arseneault et al., 2006; Bond, Carlin, Thomas, Rubin, \& Patton, 2001). Negative health consequences for those who bully others include delinquency, crime, and alcohol abuse (Magnusson, Stattin, \& Duner, 1983; Ttofi, Farrington, Lösel, \& Loeber, 2011), while those who have been both bullies and victims, also report poor peer relationships and loneliness (Nansel et al., 2001).

There is a significant conceptual and practical overlap between cyberbullying and other forms of bullying and victims of cyberbullying have been found to suffer many of the same negative consequences as victims of more traditional forms of bullying (Perren et al., 2010; Smith et al., 2008), which in extreme cases have been associated with suicide (e.g. Breguet, 2007) or suicide ideation (Hinduja \& Patchin, 2010). Those who bully others online have similarly been shown to suffer from psychological problems (Gradinger, Strohmeier, \& Spiel, 2009; Ybarra \& Mitchell, 2004a). This could point to a general association between externalizing behaviours such as bullying and other psychological difficulties or might be a result of the fact that those who bully others in cyberspace have often themselves been bullied in cyberspace (Erdur-Baker, 2010; Görzig, 2011; Li, 2007). And online bullies who have themselves been victims of online bullying reported additional difficulties. They were more likely 
to be emotionally distressed by being bullied online, had higher rates of depression, higher incidences of problem behaviour (Ybarra \& Mitchell, 2004a), and scored high in social anxiety but low in self-esteem (Kowalski, Limber, \& Agatston, 2008).

Cyberbullying might be a circular problem that does not merit a clear-cut differentiation of cyberbullies from cybervictims.

\section{Incidences of cyberbullying}

The reported incidences of cyberbullying vary largely between studies mainly due to differences in the measurement of cyberbullying and the populations studied. A comparison of children's online opportunities and risks across Europe (Hasebrink, Livingstone, Haddon \& Ólafsson, 2009) estimated that around 18\% of internet-using children had experienced some form of bullying or harassment online, with numbers ranging from 10 to 52\%. A meta-analysis on cyberbullying (Tokunaga, 2010) found that across studies on average $20-40 \%$ of youths reported being cyberbullied, ranging from $6.5 \%$ to as much as $72 \%$.

Studies assessing who cyberbullied others usually report a lower incidence of cyberbullies which might be related to a social desirability bias in responses (see Görzig, 2011). Patchin and Hinduja (2006), for example, report that 29\% of their respondents said they were online bully victims while $11 \%$ said they had bullied others online, $15 \%$ of girls in the US said they had received threatening emails while only $3 \%$ admitted to have sent such emails (Berson, Berson, \& Ferron, 2002). Among 14- to 19year-olds in Austria, 7\% were classified as cybervictims and 5\% as cyberbullies (Gradinger et al., 2009), and among 13- to 18-year-olds in the US, 49\% reported being electronic victims while 21\% said they were electronic bullies (Raskauskas \& Stoltz, 2007). However, Ybarra and Mitchell’s (2004a) study constitutes an exception, with only $4 \%$ being victims and $15 \%$ being aggressors online. 


\section{What makes a bully a cyberbully?}

Despite the large variation in the incidence of cyberbullying, the conceptual and empirical correlates are fairly consistent. Most studies assessing traditional and cyberbullying show a large overlap between the two with a high proportion of cyberbullies also being traditional bullies (34 out of 40, Gradinger et al., 2009; 17 out of 18, Raskauskas \& Stoltz, 2007; ca. 75\%, Smith et al., 2008). In addition, online bullies were found to display similar patterns of psychological traits as traditional bullies (Görzig, 2011) and cyberbullies showed similar problem behaviours as traditional bullies (Ybarra \& Mitchell, 2004a). So, what, if anything, differentiates those who bully others online and by mobile phone from those who 'merely' bully others face-to-face? And what are the factors that contribute to the migration of face-to-face bullying to cyberspace?

The main features identified are the anonymity that the internet provides, the relational nature of the aggression, advanced internet skills, high frequency of internet usage, and its 24-hour presence (e.g. Dooley, Pyzalski \& Cross, 2009; Heirman \& Walrave, 2008; Li, 2008).

Bullying others through electronic means provides the perpetrator with the possibility of staying anonymous, which may increase the power differential to the victim as well as decrease the perception of possible retaliation. Furthermore, the belief of not being detected may decrease the bully’s inhibition and possible feelings of remorse will be less likely due to the lack of feedback of the victims' emotional responses (cf. Spears, Slee, Owen, \& Johnson, 2009). In line with these arguments cyberbullies were found to name anonymity as an important feature for carrying out their actions online (Vandebosch \& van Cleemput, 2008), students indicated text messaging as the most common form of cyberbullying due to being able to remain anonymous (Smith et al., 2008), and accessing the internet in private (i.e., at home) was 
found to differentiate between harassers and non-harassers online (Ybarra \& Mitchell, 2004b).

It has been argued elsewhere that the deindividuation that can be provided by means of electronic communication can lead to disinhibition and heightened aggression (Postmes \& Spears, 1998; Postmes, Spears, \& Lea, 1998), as seen in cyberbullying. Moreover, anonymity online has been associated with two different forms of disinhibition, benign and toxic (Suler, 2004). While benign disinhibition is associated with a higher propensity of personal disclosure and a sincere self-presentation, toxic disinhibition is associated with acting on socially unacceptable impulses. Arguably, the results of a sincere self-presentation may not always be benign and acting on impulses is not necessarily always toxic. Nonetheless, two different forms of online disinhibition need acknowledging.

Traditional bullying can take the form of physical and/or relational aggression and often both go hand in hand, while electronic forms of bullying are constrained to verbal and relational aggression (e.g. insults, social exclusion, and gossip; Raskauskas \& Stoltz, 2007). Given that boys have been found to engage in more traditional bullying than girls (Nansel et al., 2001; Sourander, Helstelä, Helenius, \& Piha, 2000), but relational forms of aggression have been more commonly observed in girls (Coyne, Archer, \& Eslea, 2006), cyberbullying should be higher among girls than boys relative to traditional bullying, that is, gender differences in cyberbullying should be less pronounced or disappear. Indeed, previous studies have shown no gender differences in online harassment (Williams \& Guerra, 2007; Ybarra \& Mitchell, 2004b) or cyberbullying (Slonje \& Smith, 2008). Others found that boys were more likely to be cyberbullies than girls, especially for text messaging (Li, 2006; Slonje \& Smith, 2008); however, whether the boys in these studies were also more likely to be cyberbullies than 
girls relative to traditional bullies (i.e., whether the male:female ratio as compared to traditional bullying remained unchanged) is not known. The relational aggression of cyberbullying is further reflected in findings showing that it often takes place through SNS (Mesch, 2009) and this more often amongst girls (Smith, 2011, 2012).

A prerequisite for cyberbullying others is the ability to use and the availability of the technologies in question. Cyberbullies have been found to state that it was a means to display their technological skills (Raskauskas \& Stoltz, 2007), to hold high information and communication technology (ICT) ability beliefs (Vandebosch \& van Cleemput, 2008), and high ICT ability beliefs as well as time spent online were associated with harassing others online (Ybarra \& Mitchell, 2004b). In addition, cyberbullies were found to spend more time with ICT and engage in more risky ICT activities than traditional bullies (Erdur-Baker, 2010).

Although ICT literacy increases with age, the relationship between cyberbullying and age is less clear. In terms of cyberbully victims, some studies have shown no effect, others a positive and some a negative relationship (cf. Tokunaga, 2010). Traditional bullying in general has shown to decrease with age (e.g. for bully victims after the age of 11: Smith, Madsen, \& Moody, 1999; for bullies after the age of 11 and after the age of 7; Björkqvist, Lagerspetz, \& Kaukiainen, 1992a; Odgers et al., 2008). This has been reported to be due to the decline in the proportion of students who use physical aggression while verbal and indirect forms of aggression - also associated with cyberbullying - have been reported to increase into adolescence (Björkqvist, Österman, \& Kaukiainen, 1992b). For cyberbullying age was often not examined or no age differences were found (e.g. 11-16 year olds; Smith, Mahdavi, Carvalho, \& Tippett., 2006; 12-15 year olds; Slonje \& Smith, 2008); in contrast, higher occurrences of internet aggressors were found among 15-year-olds than among 10- to 14-year-olds 
(Ybarra \& Mitchell, 2004a). Tokanuga (2010) suggests that mixed findings concerning age effects for cyberbullying might be attributable to the diverse range of age groups studied, and suggests a curvilinear relationship with a peak at 7/8th grade.

Although these features have been postulated to distinguish cyberbullies from face-to-face bullies, to date there is no empirical evidence to our knowledge showing a direct comparison of those who exclusively bully face-to-face with those who have transgressed to bully in cyberspace (exclusively or in addition to face-to-face bullying). Most studies have either used a qualitative approach investigating self-reports of cyberbullies or others’ beliefs about them (e.g. Spears et al., 2009; Vandebosch \& van Cleemput, 2008), reporting incidences of traditional bullying, cyberbullying, or both (e.g. Patchin \& Hinduja, 2006; Slonje \& Smith, 2008; Smith et al., 2008; Ybarra \& Mitchell, 2004a), comparing cyberbullies and cybervictims with those not involved (e.g. Gradinger et al., 2009; Ybarra \& Mitchell, 2004b), or predicting cyberbullying by traditional bullying (e.g. Erdur-Baker, 2010; Li, 2007; Raskauskas \& Stoltz, 2007).

Furthermore, many authors acknowledge the role of the technological infrastructure, such as widespread mobile phone and internet penetration, to provide a platform for the occurrence of cyberbullying (e.g. Hasebrink, Livingstone, Haddon \& Ólafsson, 2009; Smith et al., 2008). It is conceivable, for example, that the proportion of cyberbullies is higher in countries in which internet or mobile use is more common or widespread than in countries where this is not the case. However, it has not yet been examined whether the migration of face-to-face to cyberbullying is in any way associated with the technological infrastructure provided.

This study addresses these issues by investigating the characteristics that differentiate face-to-face bullies and cyberbullies directly and within one cross-national 
sample. In addition, the nature of any cross-country differences due to the technological infrastructure in terms of internet access and mobile phone use is explored.

\section{Hypotheses}

We postulate the following hypotheses:

H1: Risky online activities and time spent online in general can be seen as a prerequisite for cyberbullying (Erdur-Baker, 2010). Cyberbullies will be more likely to engage in risky online activities as well as spend more time online than a face-to-face bully.

H2: Electronic forms of bullying can afford a high sense of anonymity. We acknowledge the existence of two underlying mechanisms for the association between anonymity and cyberbullying, that is, benign and toxic disinhibition (cf. Suler, 2004). This is reflected in our hypotheses regarding anonymity that cyberbullies as opposed to face-to-face bullies will be more likely to (1) show a disinhibited and thus sincere selfpresentation (i.e., have an online persona) and/or (2) be disinhibited due to the lack of social control, that is, have the possibility of accessing internet and mobile phone in private.

H3: The prevalence of unequal power relations in face-to-face bullying is often associated with physical or social power; for cyberbullying, however, power has been associated with high ICT abilities (Dooley et al., 2009; Patchin \& Hinduja, 2006). We therefore expect cyberbullies to have higher beliefs in their internet abilities than faceto-face bullies.

H4: Although males are more commonly involved in bullying than females (Sourander et al., 2000), boys and girls are equally likely to say they have harassed others online (Ybarra \& Mitchell, 2004b). Furthermore, electronic forms of contact provide a platform for verbal threats and insults which represent relational and subtle forms of 
aggression that have been more commonly observed in females (Coyne et al., 2006), in particular on SNS (Smith, 2011, 2012). Hence we assume that cyberbullies will be more likely to be female than face-to-face bullies, and that this gender difference will be stronger for those who own a SNS profile.

H5: Considering the ambiguous research evidence with respect to cyberbullying and age (cf. Tokanuga, 2010), no directional prediction is made concerning the effect of age; however, we expect the hypothesized effects of other predictors to remain constant when adjusting for age.

H6: Countries that have a higher technological infrastructure with regards to technology used by cyberbullies (i.e., higher broadband and mobile phone penetration) are thought to offer more opportunities for cyberbullying and hence show a higher ratio of cyberbullies to face-to-face bullies. In addition, we explore whether any of the other hypothesized relations can be explained by the infrastructure of the countries related to cyberbullying opportunities.

\section{Method}

A random stratified sample of approximately 1,000 internet-using children aged 9-16 was interviewed in each of 25 European countries. The total sample size was 25,142 (12,501 girls); additionally, one parent of each child was interviewed.

The questionnaire, translated and back-translated from English into 24 languages, underwent cognitive testing and pilot testing to aid completion by the children. Interviews took place during 2010 in children’s homes, conducted face-to-face but with private questionnaire completion for sensitive questions. Average interview time per child was 45 minutes (see also Görzig, 2012; Livingstone, Haddon, Görzig, \& Ólafsson, 2011). 


\section{Dependent measure}

Cyberbullying

Respondents were given the following introductory text: 'Sometimes children or teenagers say or do hurtful or nasty things to someone and this can often be quite a few times on different days over a period of time, for example. This can include: teasing someone in a way this person does not like, hitting, kicking or pushing someone around, leaving someone out of things' followed up by the question 'Have you acted in a way that might have felt hurtful or nasty to someone else in the PAST 12 MONTHS?' Those who had chosen 'Yes' as the response option for this question were further asked how they had done so.

Those who had chosen the response options 'By mobile phone [...]' and/or 'On the internet' were grouped as cyberbullies (coded ' 1 ') and those who had not chosen either of these options but the option 'In person face-to-face' were categorized as having bullied exclusively face-to-face (henceforth referred to as face-to-face bullies, coded ' 0 ') ' $^{1}$

\section{Independent measures}

Minutes online per day was calculated by multiplying the answer from the question 'About how long do you spend using the internet on a normal school day' with 5 and the answer to the question 'About how long do you spend using the internet on a normal non-school day?' with 2 . The results were summed and divided by 7 to yield an

\footnotetext{
${ }^{1}$ We note that the definition of cyberbullying specifies a power differential between bully and victim as well as the bully's intention that are not immediately apparent in the operationalization. However, in line with the literature we assume intention by the bully's awareness as indicated through assent to this question while the power differential in cyberbullying has been associated with computer literacy (Patchin \& Hinduja, 2006) and the offender's anonymity (Ybarra \& Mitchell, 2004b), which were assessed separately.
} 
estimate for minutes online per day. To eliminate outliers the highest and lowest $5 \%$ were recoded as 20 and 240 minutes, respectively.

Risky online activities - risky internet use has been defined differently by different authors. Erdur-Baker (2010), for example, assessed risky usage of 'internet-mediated communication tools' via three items ('asked someone you met on the internet to meet face-to-face?', 'disclosed your personal information to unknown people over the internet, including password and username?' and 'accepted an invitation to meet in person someone you met over the internet?'). We chose to assess risky usage defined as risky online activities in the work of EU Kids Online (cf. Livingstone, Haddon, \& Görzig, 2012). Items overlap with those used by other authors; the focus here, however, is on the interaction with other people online.

Risky online activities was measured by the number out of five options ('Looked for new friends on the internet', 'Added people to my friends list or address book who I have never met face-to-face’, 'Pretended to be a different kind of person on the internet from who I really am', 'Sent personal information to someone who I have never met face-to-face’, 'Sent a photo or video of myself to someone I have never met face-to-face’ $[\alpha=0.73$, adapted from the UK Children Go Online survey; Livingstone \& Helsper, 2010).

Anonymity was assessed via two aspects. The first measure, associated with disinhibition due to a genuine self-presentation, was assessed by an online persona scale composed of three items: 'I find it easier to be myself on the internet than when I am with people face-to-face', 'I talk about different things on the internet than I do when speaking to people face-to-face', 'On the internet I talk about private things which I do not share with people face-to-face'. The mean of the response options ranging from 1 (not true) to 3 (very true) was taken $(\alpha=0.65)$. The second measure, associated with 
disinhibition due to lack of social control, assessed respondents’ private access as indicated by whether they stated that they used the internet on their mobile device ${ }^{2}$ and/or from a private room at home (coded ' 1 ') or not (coded '0'). Both measures tap into two different aspects of anonymity associated with disinhibitory processes.

Beliefs about internet abilities was measured by one item, 'I know lots of things about using the internet’ with responses ranging from 1 (not true) to 3 (very true).

Social networking site (SNS) use was taken from respondents' answers as to whether they had a profile on a SNS (coded ' 1 ') or not (coded ' 0 ').

Demographic variables were entered with gender (male $=0$, female $=1$ ) and age $(M=13.06)$.

\section{Results}

\section{Correlations}

Correlations were performed on the subset of children who had either been grouped as a cyber- or face-to-face bully ( $n=2,821)$. All hypothesized predictors were significantly correlated with cyberbullying with effect sizes (cf. Cohen, 1992), ranging from small (e.g. gender) to medium (e.g. risky online activities). In addition, there were notable significant correlations between predictor variables, especially for age and SNS (see Table 1).

Table 1 about here

\footnotetext{
${ }^{2}$ Mobile phones were reported to be the most frequently used media for cyberbullying and this mostly in private (Smith et al., 2008).
} 


\section{Predicting cyberbullying}

The following analyses were performed in two subsequent steps. First, a hierarchical logistic regression was carried out in order to assess the contribution of different blocks of independent variables. Then the final model of the logistic regression was analysed using multi-level modelling in order to assess country differences. For the hierarchical logistic regression all variables were standardized to range from 0 to 1 in order to make coefficients comparable. Further, non-dichotomous variables were centred at their grand mean for multi-level modelling.

\section{Individual differences}

Testing hypotheses one through four all predictor variables except age were entered in the first step of the analysis (see Table 2). Children who spent more time online, engaged in risky online activities, held a higher online persona, and higher beliefs in their internet abilities were shown to be significantly more likely to bully on the internet or mobile phone than exclusively face-to-face. Also, girls were more likely to be a cyber- as opposed to a face-to-face bully. However, SNS and private access were not statistically significant. Hence, hypothesis two was only partially confirmed. Beliefs in internet abilities showed the lowest coefficient with the likelihood that a child was a cyberbully as opposed to having bullied exclusively face-to-face increasing by $43 \%$ from the lowest to the highest end of the scale. The likelihood increase for cyberbullying was highest, with 336\% for risky online activities - more than three times as high as for any of the other predictors.

To test the assumption of hypothesis four, an interaction effect of SNS and gender was added in the second step of the analysis. Confirming our prediction, the interaction was significant while gender became insignificant. Coefficients for the other 
predictors did not change considerably. To explore the gender by SNS interaction further we inspected the ratio of cyberbullies amongst bullies for boys and girls with and without a social networking profile. Overall, the percentage of cyberbullies was higher amongst those with a SNS. However, this difference was particularly strong for girls. Furthermore, the higher percentage of cyberbullies amongst bullies for girls compared to boys only occurred amongst those having a social networking profile (see Figure 1).

Figure 1 about here

In the third and last step of the analysis, testing hypothesis five, we adjusted for age. Age was a significant predictor for cyberbullying with the likelihood to be a cyberbully increasing by $95 \%$ between ages $9-16$. Also, as suggested by the significant intercorrelations with age, the predicted increase in cyberbullying through time spent online, risky online activities, and online persona dropped by ca. 10-20\% as compared to previous steps of the analysis, yet coefficients remained significant. However, contrary to predictions, beliefs in internet abilities became insignificant after adding age.

Table 2 about here

\section{Cross-country differences}

Multi-level modelling was used to account for cross-national variation. As a first step a model not including any predictors was conducted to assess the variation of cyber- as opposed to face-to-face bullying across countries. The variation was significant $\left(\chi_{(1)}^{2}=35.94, p<0.001\right)$, with $3.3 \%$ of the variation in cyberbullying being attributable to between country differences (variance partitioning coefficient; cf. Browne, Subramanian, Jones, and Goldstein, 2005). The odds of cyberbullies among cyber- and 
face-to-face bullies was significantly lower from the overall odds in Greece while they were significantly higher in Romania, Belgium, Estonia, and Sweden (see Figure 2).

Figure 2 about here

As a second step the predictors from the hierarchical linear regression were entered leaving a significant variation of $2.7 \%$ in cyberbullying unexplained between countries $\left(\chi_{(1)}^{2}=20.67, p<0.001\right)$.

As a third step it was tested whether the relationships between predictors and cyberbullying would vary between countries. Only risky online activities showed significant cross-country variation as a predictor for cyberbullying $\left(\chi_{(2)}^{2}=6.32, p<0.05\right)$. Surprisingly, countries with a lower intercept showed a stronger relationship with risky online activities, that is, in countries with fewer cyberbullies, cyberbullying was more strongly related to risky online activities ( $r=-0.82, p<0.001)$. Cyberbullying had the weakest relationships to risky online activities in Romania $(\operatorname{Exp}(B)=1.90)$ and the UK $(\operatorname{Exp}(B)=2.25)$ and strongest in the Netherlands $(\operatorname{Exp}(B)=7.16)$ and Bulgaria $(\operatorname{Exp}(B)$ 8.07).

In a fourth step it was tested whether contextual factors concerning the countries' technological infrastructure could explain the cross-country variation in cyberbullying and/or in the association of cyberbullying with risky online activities. The countries’ broadband penetration (i.e., the percentage of households using broadband connections; Eurostat, 2009) and mobile penetration (i.e., mobile phones per 100 inhabitants; Eurostat, 2008) were standardized to range from 0 to 1 and mean-centred. Broadband penetration could neither explain cross-country variation in cyberbullying $(\operatorname{Exp}(B)=1.02, p=0.94)$ nor the association with risky online activities $(\operatorname{Exp}(B)=0.74$, $p=0.65)$. However, the countries’ mobile penetration could partially explain crosscountry variation in cyberbullying $(\operatorname{Exp}(B)=0.45, p<0.05)$ which was further due to 
cross-country variation in the relationship with risky online activities $(\operatorname{Exp}(B)=6.54$, $p<0.01)$ and improved the model fit $\left(\chi_{(2)}^{2}=8.29, p<0.05\right)$. The relationship of risky online activities with cyberbullying was stronger in countries with higher mobile phone penetration and country differences in cyberbullying decreased when risky online activities were high (see Figure 3).

Figure 3 about here

\section{Discussion}

Across the 25 European countries studied, those children who bully others via the internet or a mobile device differ significantly from those who bully others face-to-face only. In line with previous research (e.g. Erdur-Baker, 2010; Kowalski et al., 2008; Ybarra \& Mitchell, 2004b) cyberbullies (all else being equal) were at least four times as likely to engage in risky online activities, and twice as likely to spend more time online as well as finding it easier to be themselves online.

In contrast with earlier findings suggesting that online harassers can be differentiated from non-harassers by accessing the internet at home (Ybarra \& Mitchell, 2004b), whether children had private access to their mobile phones or computer did not make a difference. Possibly, a differentiation is needed between those cyberbullies who bully by mobile phone and those who bully online via computers. In the current study we assessed both. However, the main form of cyberbullying is suggested to be phone calls and text messaging (cf. Smith et al., 2008), cybervictims who are bullied via mobile devices are more likely to use the internet on the go ( Görzig \& Frumkin, in press), and the risk of cyberbullying increases for children using a smartphone (Stald \& Ólafson, 2012). Perhaps the recent increase in internet mobility makes private access less important for cyberbullying. 
When looking at bullies only, girls were more likely to be cyberbullies than face-to-face bullies compared to boys. This is in line with theories and research about gender differences and aggression as girls are more prone to relational aggression than boys (Coyne et al., 2006); this is more prominent in cyberspace (Raskauskas \& Stoltz, 2007). Further, it was shown that the gender difference that shows girls more likely to be cyberbullies than boys only holds amongst those who have a SNS profile. Given that SNS are used for social relations online and can be a source for adolescents' social selfesteem and well-being (Valkenburg, Peter, \& Schouten, 2006), this finding supports girls’ higher tendency to relational aggression as compared to boys, and suggests that the main medium for relational aggression amongst cyberbullies might be SNS. Future research is needed to investigate the nature of the aggressive acts carried out and associated cyberspaces more closely.

Confirming previous research, the likelihood of being a cyberbully also increased with beliefs about internet abilities. However, this effect disappears when age is added in the last step of the regression. The fact that cyberbullying increases with age might confirm previous assertions that a peak of cyberbullying occurs around the age of the older children in the sample (i.e., early teens; Tokanuga, 2010). Age and ability beliefs have been reasonably correlated, and the likelihood of cyberbullying amongst bullies increases with both. Due to the nature of this cross-sectional study, we are unable to make any causal statements, but it is possible that the likelihood of cyberbullying increases with (1) age, due to a rise in beliefs in one's internet abilities or (2) higher beliefs in one's internet abilities due to factors associated with age (e.g. higher availability of mobile and ICT devices), or both. Longitudinal and perhaps quasiexperimental studies might disentangle the effects of age and internet ability beliefs in the future. 


\section{Country differences}

The between-country differences in the amount of bullies who had taken up cyberbullying were very low. Nonetheless, countries did differ significantly from one another in their odds of cyberbullying compared to face-to-face bullying, and four countries out of 25 were clearly different from the overall odds. It is generally difficult to find predictors that can explain little, albeit significant, variation (here 3.3\%). The hypothesized external indicator of broadband penetration did not succeed in explaining country differences or associations with cyberbullying. Perhaps surprisingly, a country’s higher mobile penetration was associated with a lower amount of cyberbullying. This could be explained by the degree to which individuals’ risky online activities varied across countries in predicting cyberbullying that in turn was associated with the country's mobile phone penetration. The higher a country’s mobile phone penetration, the stronger the relationship between risky online activities and cyberbullying.

The fact that a country's mobile penetration could partially explain country differences in cyberbullying but a country’s broadband penetration did not might underline that mobile phones are the most common devices used for cyberbullying (cf. Smith et al., 2008), and mobile devices are increasingly used to access the internet, elevating their potential for cyberbullying (e.g. Office for National Statistics [ONS], 2011). However, why individuals’ risky online activities as a predictor for cyberbullying varied with countries' mobile penetration is not straightforward. In line with our initial argument that adolescents increasingly use the internet on their mobile phones, risky online activities perhaps serve as a proxy for risky activities on devices used to access the internet in general. Furthermore, the findings suggest that adolescents' risky activities play a stronger role for the migration from face-to-face to cyberbullying when a country’s technological infrastructure (i.e., mobile phone penetration) provides wider platforms for cyberbullying. Surprisingly, however, for 
adolescents who engage strongly in risky online activities, the context of the technological infrastructure does not seem to matter (i.e., the country variation is low when risky online activities are high). For those who engage in risky online activities less than the average, cyberbullying is more likely the lower the country's provision of technological infrastructure (i.e., mobile phone penetrations). Quite possibly factors associated with country variation in cyberbullying are complex and hard to detect when variation between countries is low. Further, this perhaps only confirms that the explanatory power in explaining cyberbullying lies on the individual rather than the country-level variables.

\section{Implications and conclusions}

This study confirms within one cross-national sample some of the key findings previously found in several separate studies (e.g., Erdur-Baker, 2010; Smith, 2011, 2012; Vandebosch \& van Cleemput, 2008). In addition, it has shown that the predictors for cyberbullying among bullies are remarkably stable across countries, indicating that the migration of face-to-face to cyberbullying is not a function of the national (e.g. cultural, technological, or regulatory) context. Rather it seems that amongst adolescent bullies who use the internet, the likelihood to cyberbully is a function of individual characteristics such as patterns of usage (e.g. time spent and activities online, cyberspaces visited) and preferences that can be fulfilled by the online environment (e.g. disinhibited self-presentation).

Overall this study suggests that the migration of bullying to cyberbullying is related to the time that adolescents spend online, their risky activities, and their ability to be more themselves in the absence of social control, that is, to stay anonymous. In addition, the use of SNS is associated with the migration to cyberbullying, particularly amongst girls. However, it is not suggested that those characteristics are causally related 
to cyberbullying and imply merely negative consequences. On the contrary, the anonymity that online communication can provide, for example, has also been associated with the disclosure of personal information and seeking of advice that might not have been attempted elsewhere, particularly by those who feel less confident in the offline world (Livingstone \& Helsper, 2007).

Considering that those who cyberbully others and those being cyberbullied are often the same (Erdur-Baker, 2010; Görzig, 2011; Li, 2007), predictors identified in this study and steps suggested to prevent negative health consequences are likely to hold for both groups. In a similar vein, the ambiguous patterns and low variation of country differences of cyberbullying and its characteristics suggest that pathways across countries to tackle cyberbullying could be similar.

\section{Limitations and future directions}

Despite the low between-country effect in the occurrence of cyberbullying, future studies should investigate why certain countries show a stronger migration from face-toface to cyberbullying than others. Patterns within the interrelations between predictor variables, such as age and beliefs in internet abilities, also need further uncovering. Considering that the EU Kids Online II survey exclusively sampled children who use the internet, the findings are limited to those face-to-face bullies who already use the internet. Different results might be expected when also looking at those face-toface bullies who do not have the opportunity to go online.

Steps towards preventing cyberbullying, in addition to those taken to prevent bullying in general, should support and mediate adolescents 'cyber-behaviours', in particular to use electronic means of communication in a pro-social way, and enhance self-awareness to prevent the negative effects of deindividuation while at the same time remaining cautious not to restrict online opportunities. More research is needed to 
identify constructive mediation strategies that are not restrictive to opportunities (Livingstone \& Helsper, 2008). There is some evidence that parental evaluative mediation strategies can have a protective effect towards cyberbullying (Mesch, 2009). Particular attention should be paid to those who are already prone to bully others faceto-face - not only to prevent adolescents from cyberbullying others and the negative consequences associated with it for both, but also to prevent them from being cyberbullied by others.

This study is a further step towards revealing the characteristics of cyberbullies, although it is limited to a comparison with those who bully face-to-face only. Further investigation is needed to examine the relations amongst those who bully face-to-face only, face-to-face and in cyberspace, in cyberspace only, ${ }^{3}$ and further to differentiate between those who bully via the internet from those who use mobile devices (cf. Görzig \& Frumkin, in press). In addition, as there is a huge overlap between victims and perpetrators of bullying (Smith et al., 2008), there is a need to examine the complex relations between these groups online and offline. Identifying the characteristics behind this relatively new form of bullying could be a step forward to address the issues for those working in the child sector, bullying prevention and policy makers.

\footnotetext{
${ }^{3}$ The routing procedures inherent in the EU Kids Online II survey do not permit the matching of predictor variables across all groups.
} 


\section{References}

Arseneault, L., Walsh, E., Trzesniewski, K., Newcombe, R., Caspi, A., \& Moffitt, T.E. (2006). Bullying victimization uniquely contributes to adjustment problems in young children: A nationally representative cohort study. Pediatrics, 118, 130-138.

Berson, I. R., Berson, M. J., \& Ferron, J. M. (2002). Emerging risks of violence in the digital age: Lessons for educators from an online study of adolescent girls in the United States. Journal of School Violence, 1(2), 51-72.

Björkqvist, K., Lagerspetz, K. M., \& Kaukiainen, A. (1992a). Do girls manipulate and boys fight? Developmental trends in regard to direct and indirect aggression. Aggressive Behavior, 18(2), 117-127.

Björkqvist, K., Österman, K., \& Kaukiainen, A. (1992b). The development of direct and indirect aggressive strategies in males and females. In K. Björkqvist, P. Niemelä, K. Björkqvist, P. Niemelä (Eds.), Of mice and women: Aspects of female aggression (pp. 51-64). San Diego, CA: Academic Press.

Bond, L., Carlin, J. B., Thomas, L., Rubin, K., \& Patton, G. (2001). Does bullying cause emotional problems? A prospective study of young teenagers. British Medical Journal, 323, 480-484.

Breguet, T. (2007). Frequently asked questions about cyberbullying. New York: The Rosen Publishing Group, Inc.

Browne, W. J., Subramanian, S. V., Jones, K., \& Goldstein, H. (2005). Variance partitioning in multilevel logistic models that exhibit overdispersion. Journal of the Royal Statistical Society: Series A (Statistics in Society), 168, 599-613.

Cohen, J. (1992). A power primer. Psychological Bulletin, 112(1), 155-159. 
Coyne, S. M., Archer, J., \& Eslea, M. (2006). “We're not friends anymore! Unless...”: The frequency and harmfulness of indirect, relational, and social aggression. Aggressive Behavior, 32, 294-307.

Dooley, J.J., Pyzalski, J., \& Cross, D. (2009). Cyberbullying and face-to-face bullying: Similarities and differences. Zeitschrift für Psychologie/Journal of Psychology, 217(4), 182-188.

Erdur-Baker, Ö. (2010). Cyberbullying and its correlation to traditional bullying, gender and frequent and risky usage of internet-mediated communication tools. New Media \& Society, 12(1), 109-125.

Eurostat (2008). Mobile phone subscriptions per 100 inhabitants. Retrieved from http://epp.eurostat.ec.europa.eu/tgm/table.do?tab=table\&init=1\&language=en\&pcode $=$ tin00060\&plugin $=1$

Eurostat (2009). Households with broadband access - Percentage of households with at least one member aged 16 to 74 . Retrieved from http://epp.eurostat.ec.europa.eu/tgm/table.do?tab=table\&init=1\&language=en\&pcode $=$ tin00089\&plugin $=1$

Forero, R., McLellan, L., Rissel, C., \& Baumann, A. (1999). Bullying behaviour and psychosocial health among school students in New South Wales, Australia: Cross sectional survey. British Medical Journal, 319, 344-351.

Gradinger, P., Strohmeier, D., \& Spiel, C. (2009). Traditional bullying and cyberbullying: Identification of risk groups for adjustment problems. Zeitschrift für Psychologie/Journal of Psychology, 217(4), 205-213.

Görzig, A. (2011). Who bullies and who is bullied online? EU Kids Online - Short Report. London, UK: London School of Economics and Political Science. 
Görzig, A. (2012). Methodological framework: the EU Kids Online project. In S. Livingstone, L. Haddon, and A. Görzig (Eds.), Children, risk and safety online: Research and policy challenges in comparative perspective (pp. 15-32). Bristol: The Policy Press.

Görzig, A., \& Frumkin, L. (in press). Cyberbullying experiences on-the-go: How social media can become distressing. Cyberpsychology.

Hasebrink, U., Livingstone, S., Haddon, L., \& Ólafsson, K. (2009) Comparing children’s online opportunities and risks across Europe: Cross-national comparisons for EU Kids Online. LSE, London: EU Kids Online. 2nd ed.

Hawker, D.S.J. \& Boulton, M.J. (2000). Twenty years’ research on peer victimization and psychosocial maladjustment: A meta-analytic review of cross-sectional studies. Journal of Child Psychiatry and Psychiatry, 41, 441-455.

Heirman, W. \& Walrave, M. (2008). Assessing concerns and issues about the mediation of technology in cyberbullying. Cyberpsychology: Journal of Psychosocial Research on Cyberspace, 2(2), article 1. Retrieved from http://cyberpsychology.eu/view.php?cisloclanku=2008111401\&article=1

Hinduja, S. \& Patchin, J. W. (2010). Bullying, cyberbullying, and suicide. Archives of Suicide Research, 14(3), 206-221.

Kim, Y.S., Koh, Y.J., \& Leventhal, B. (2005). School bullying and suicidal risk in Korean middle school students. Pediatrics, 115, 357-363.

Kowalski, R. M., Limber, S. P., \& Agatston, P. W. (2008). Cyber bullying: Bullying in the digital age. Malden: Blackwell Publishing.

Kumpulainen K., Räsänen E., \& Henttonen I. (1998). Bullying and psychiatric symptoms among elementary school-age children. Child Abuse \& Neglect, 22(7), 705-717. 
Li, Q. (2006). Cyberbullying in schools: A research of gender differences. School Psychology International, 27, 157-170.

Li, Q. (2007). New bottle but old wine: A research of cyberbullying in schools. Computers in Human Behavior, 23(4), 1777-1791.

Li, Q. (2008). A cross-cultural comparison of adolescents’ experience related to cyberbullying. Educational Research, 50(3), 223-234.

Livingstone, S. \& Helsper, E. J. (2007). Taking risks when communicating on the internet: The role of offline social-psychological factors in young people’s vulnerability to online risks. Information, Communication \& Society, 10(5), 619-644.

Livingstone, S. \& Helsper, E. J. (2008). Parental mediation of children’s internet use. Journal of Broadcasting \& Electronic Media, 52(4), 581-599.

Livingstone, S. \& Helsper, E. (2010). Balancing opportunities and risks in teenagers' use of the internet: The role of online skills and internet self-efficacy. New Media \& Society, 12(2), 309-329.

Livingstone, S., Haddon, L., \& Görzig, A. (2012). Children, risk and safety on the internet: Kids online in comparative perspective. Bristol: The Policy Press.

Livingstone, S., Haddon, L. G., Görzig, A., \& Ólafsson, K. (2011). Risks and safety on the internet: The perspective of European children - Full findings and policy implications from the EU Kids Online survey of 9-16 year olds and their parents in 25 countries. London: London School of Economics and Political Science.

Magnusson, D., Statten, H., \& Duner, A. (1983). Aggression and criminality in a longitudinal perspective. In K. T. van Dusen \& S. A. Mednick (Eds.), Prospective studies of crime and delinquency (pp. 277-301). Netherlands: Kluwer Nijoff. 
Menesini, E. \& Nocentini, A. (2009). Cyberbullying definition and measurement: Some critical considerations. Zeitschrift für Psychologie/Journal of Psychology, 217(4), 230-232.

Mesch, G. S. (2009). Parental mediation, online activities, and cyberbullying. Cyberpsychology \& Behavior, 12(4), 387-393.

Nansel, T. R., Overpeck, M. D., Haynie, D. L., Ruan, W. J., \& Scheidt, P. C. (2003). Relationships between bullying and violence among US youth. Archives of paediatrics and adolescent medicine, 157(4), 348-353.

Nansel, T. R., Overpeck, M. D., Pilla, R. S., Ruan, W. J., Simons-Morton, B., \& Scheidt, P. (2001). Aggression behaviors among US youth: Prevalence and association with psychosocial adjustment. Journal of the American Medical Association, 285(16), 2094-2100.

Odgers, C. L., Moffitt, T. E., Broadbent, J. M., Dickson, N., Hancox, R. J., Harrington, H., \& Caspi, A. (2008). Female and male antisocial trajectories: From childhood origins to adult outcomes. Development and Psychopathology, 20(2), 673-716.

Olweus, D. (1993). Bullying at school: What we know and what we can do. Cambridge, MA: Blackwell.

ONS (Office for National Statistics) (2011). Internet access - Households and individuals. Retrieved from www.ons.gov.uk/ons/dcp171778_227158.pdf

Patchin, J. W. \& Hinduja, S. (2006). Bullies move beyond the schoolyard: A preliminary look at cyberbullying. Youth Violence and Juvenile Justice, 4(2), 148-169.

Perren, S., Dooley, J., Shaw, T., \& Cross, D. (2010). Bullying in school and cyberspace: Associations with depressive symptoms in Swiss and Australian adolescents. Child and Adolescent Psychiatry and Mental Health, 28(4), 1-10. 
Postmes, T. \& Spears, R. (1998). Deindividuation and anti-normative behavior: A metaanalysis. Psychological Bulletin, 123(3), 238-259.

Postmes, T., Spears, R., \& Lea, M. (1998). Breaching or building social boundaries? SIDEeffects of computer-mediated communication. Communication Research, 25(6), 689715.

Raskauskas, J. \& Stoltz, A. D. (2007). Involvement in traditional and electronic bullying among adolescents. Developmental Psychology, 43(3), 564-575.

Slonje, R. \& Smith, P. K. (2008). Cyberbullying: Another main type of bullying? Scandinavian Journal of Psychology, 49(2), 147-154.

Slonje, R., Smith, P. K. \& Frisen, A. (in press). The nature of cyberbullying, and strategies for prevention. Computers in Human Behavior (2012), http://dx.doi.org/10.1016/j.chb.2012.05.024

Smith, P. K. (2011). Progress in cyberbullying research. Paper presented at the conference Children, risk and safety online: Research and policy challenges in comparative perspective, 22-23 September, London, UK.

Smith, P. K. (2012). Cyberbullying and cyber aggression. In S. R. Jimerson, A. B. Nickerson, M. J. Mayer, \& M. J. Furlong (Eds.), Handbook of school violence and school safety: International research and practice (pp. 93-103). New York: Routledge.

Smith, P. K., Madsen, K., \& Moody, J. (1999). What causes the age decline in reports of being bullied in school? Towards a developmental analysis of risks of being bullied. Educational Research, 41, 267-285.

Smith, P. K., Mahdavi, J., Carvalho, M., \& Tippett, N. (2006). An investigation into cyberbullying, its forms, awareness and impact, and the relationship between age and 
gender in cyberbullying. Research Brief No. RBX03-06. London: Department for Education and Skills.

Smith, P. K., Mahdavi, J., Carvalho, M., Fisher, S., Russell, S., \& Tippett, N. (2008). Cyberbullying: Its nature and impact in secondary school pupils. Journal of Child Psychology and Psychiatry, 49(4), 376-385.

Sourander, A., Helstelä, L., Helenius, H., \& Piha, J. (2000). Persistence of bullying from childhood to adolescence - a longitudinal 8-year follow-up study. Child Abuse \& Neglect, 24(7), 873-881.

Spears, B., Slee, P., Owens, L., \& Johnson, B. (2009). Behind the scenes and screens: Insights into the human dimension of covert and cyberbullying. Zeitschrift für Psychologie/Journal of Psychology, 217, 189-196.

Stald \& Ólafsson, K. (2012). Mobile access, different users, different risks, different consequences? In Livingstone, S., Haddon, L., and Görzig, A. (Eds.).Children, risk and safety online: Research and policy challenges in comparative perspective. Bristol: The Policy Press.

Suler, J. (2004). The online disinhibition effect. Cyberpsychology \& Behavior, 7(3), 321-326. Tokunaga, R. S. (2010). Following you home from school: A critical review and synthesis of research on cyberbullying victimization. Computers in Human Behavior, 26(3), 277287.

Ttofi, M. M., Farrington, D. P., Lösel, F., \& Loeber, R. (2011). The predictive efficiency of school bullying versus later offending: A systematic/meta-analytic review of longitudinal studies. Criminal Behaviour And Mental Health, 21(2), 80-89. 
Valkenburg, P. M., Peter, J., \& Schouten, A. P. (2006). Friend networking sites and their relationship to adolescents’ well-being and social self-esteem. CyberPsychology \& Behavior, 9(5), 584-590.

Vandebosch, H. \& van Cleemput, K. (2008). Defining cyberbullying: A qualitative research into the perceptions of youngsters. CyberPsychology \& Behavior, 11, 499-503.

Williams, K. R. \& Guerra, N. G. (2007). Prevalence and predictors of internet bullying. Journal of Adolescent Health, 41, S14-S21.

Ybarra, M. L. \& Mitchell, K. J. K. (2004a). Online aggressor/targets, aggressors, and targets: A comparison of associated youth characteristics. Journal of Child Psychology and Psychiatry, 45(7), 1308-1316.

Ybarra, M. L. \& Mitchell, K. J. K. (2004b). Youth engaging in online harassment: Associations with caregiver-child relationships, internet use, and personal characteristics. Journal of Adolescence, 27, 319-336. 


\section{Tables and figures}

Table 1. Descriptive statistics and intercorrelations among predictor variables and cyberbullying among bullies

\begin{tabular}{|c|c|c|c|c|c|c|c|c|c|c|c|}
\hline & $\begin{array}{c}\text { Range or number } \\
\text { (scale) }\end{array}$ & & & & & & Cor & lations & & & \\
\hline 1. Gender & Male $=0$ & 0.45 & 0.50 & 1.00 & & & & & & & \\
\hline 3. Minutes online & $20-240$ & 111 & 67 & -0.01 & $0.36^{* *}$ & 1.00 & & & & & \\
\hline $\begin{array}{l}\text { 4. Risky online } \\
\text { activities }\end{array}$ & $0-5$ & 1.83 & 1.55 & 0.00 & $0.28^{* *}$ & $0.29^{* *}$ & 1.00 & & & & \\
\hline 6. Private access & No $=0$ & 0.74 & 0.44 & 0.00 & $0.27^{* *}$ & $0.27^{* *}$ & $0.17^{* *}$ & $0.06^{* *}$ & 1.00 & & \\
\hline $\begin{array}{l}\text { 7. Beliefs about } \\
\text { internet abilities }\end{array}$ & $1-3$ & 2.35 & 0.66 & $-0.08^{* *}$ & $0.34^{* *}$ & $0.29^{* *}$ & $0.21^{* *}$ & $0.10^{* *}$ & $0.23^{* *}$ & 1.00 & \\
\hline 8. SNS & $\mathrm{No}=0$ & 0.73 & 0.44 & $0.07^{* *}$ & $0.41^{* *}$ & $0.31^{* *}$ & $0.33^{* *}$ & $0.11^{* *}$ & $0.24^{* *}$ & $0.29^{* *}$ & 1.00 \\
\hline 9. Cyberbullying & Face-to-face $=0$ & 0.32 & 0.46 & $0.09^{* *}$ & $0.21^{* *}$ & $0.20^{* *}$ & $0.27^{* *}$ & $0.13^{* *}$ & $0.12^{* *}$ & $0.14^{* *}$ & $0.17^{* *}$ \\
\hline
\end{tabular}

Notes: Analysis was performed on those children who had indicated to have bullied someone else face-to-face, by mobile phone, or on the internet $(n=2,821)$. Coefficients for correlations between dichotomous and continuous measures are point-biserial $\left(r_{p b}\right)$ and between two dichotomous measures are measured by $\chi^{2}$-analyses and indicated by $\Phi$.

** Correlation is significant at the 0.01 level (2-tailed). 
Table 2. Summary of hierarchical logistic regression analysis for variables predicting cyberbullying among bullies $(n=2,597)$

\begin{tabular}{|c|c|c|c|c|c|c|c|c|c|}
\hline \multirow[b]{2}{*}{ Variable } & \multicolumn{3}{|c|}{ Step 1} & \multicolumn{3}{|c|}{ Step 2} & \multicolumn{3}{|c|}{ Step 3} \\
\hline & $B$ & SE B & $\operatorname{Exp}(B)$ & $B$ & $S E B$ & $\operatorname{Exp}(B)$ & $B$ & $S E B$ & $\operatorname{Exp}(B)$ \\
\hline Constant & -2.52 & 0.17 & $0.08 * * *$ & -2.33 & 0.18 & $0.10 * * *$ & -3.33 & 0.32 & $0.08 * * *$ \\
\hline Gender & 0.45 & 0.09 & $1.56 * * *$ & -0.03 & 0.22 & 0.97 & -0.06 & 0.22 & 0.94 \\
\hline Minutes online & 0.68 & 0.15 & $1.98 * * *$ & 0.65 & 0.16 & $1.92 * * *$ & 0.53 & 0.16 & $1.70 * * *$ \\
\hline Risky online activities & 1.47 & 0.15 & $4.36 * * *$ & 1.50 & 0.15 & $4.47 * * *$ & 1.44 & 0.16 & $4.23 * * *$ \\
\hline Online persona & 0.66 & 0.18 & $1.94^{* * *}$ & 0.66 & 0.18 & $1.94 * * *$ & 0.72 & 0.18 & $2.05 * * *$ \\
\hline Private access & 0.12 & 0.11 & 1.13 & 0.13 & 0.11 & 1.13 & 0.08 & 0.11 & 1.08 \\
\hline $\begin{array}{l}\text { Beliefs about internet } \\
\text { abilities }\end{array}$ & 0.35 & 0.15 & $1.43^{*}$ & 0.35 & 0.15 & $1.42 *$ & 0.25 & 0.15 & 1.28 \\
\hline SNS & 0.19 & 0.12 & 1.21 & -0.05 & 0.16 & 0.95 & -0.17 & 0.16 & 0.84 \\
\hline Gender x SNS & & & & 0.58 & 0.24 & $1.79 *$ & 0.60 & 0.24 & $1.82 *$ \\
\hline Age & & & & & & & 0.67 & 0.17 & $1.95 * * *$ \\
\hline $\begin{array}{l}\text { Nagelkerke- } R^{2} \\
-2 \text { Log likelihood } \\
\text { ratio }\end{array}$ & \multicolumn{3}{|c|}{0.14} & \multicolumn{3}{|c|}{$\begin{array}{c}0.14 \\
6.07(1)^{*}\end{array}$} & \multicolumn{3}{|c|}{$\begin{array}{l}0.15 \\
15.499(1)^{* * *}\end{array}$} \\
\hline
\end{tabular}


Figure 1

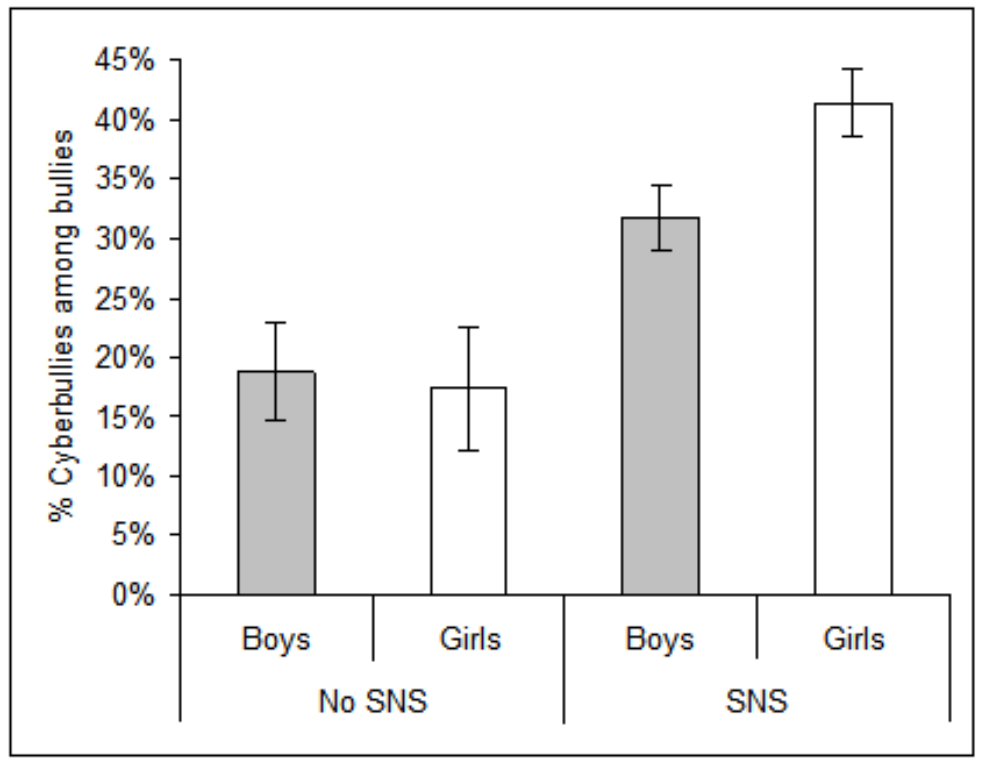


Figure 2

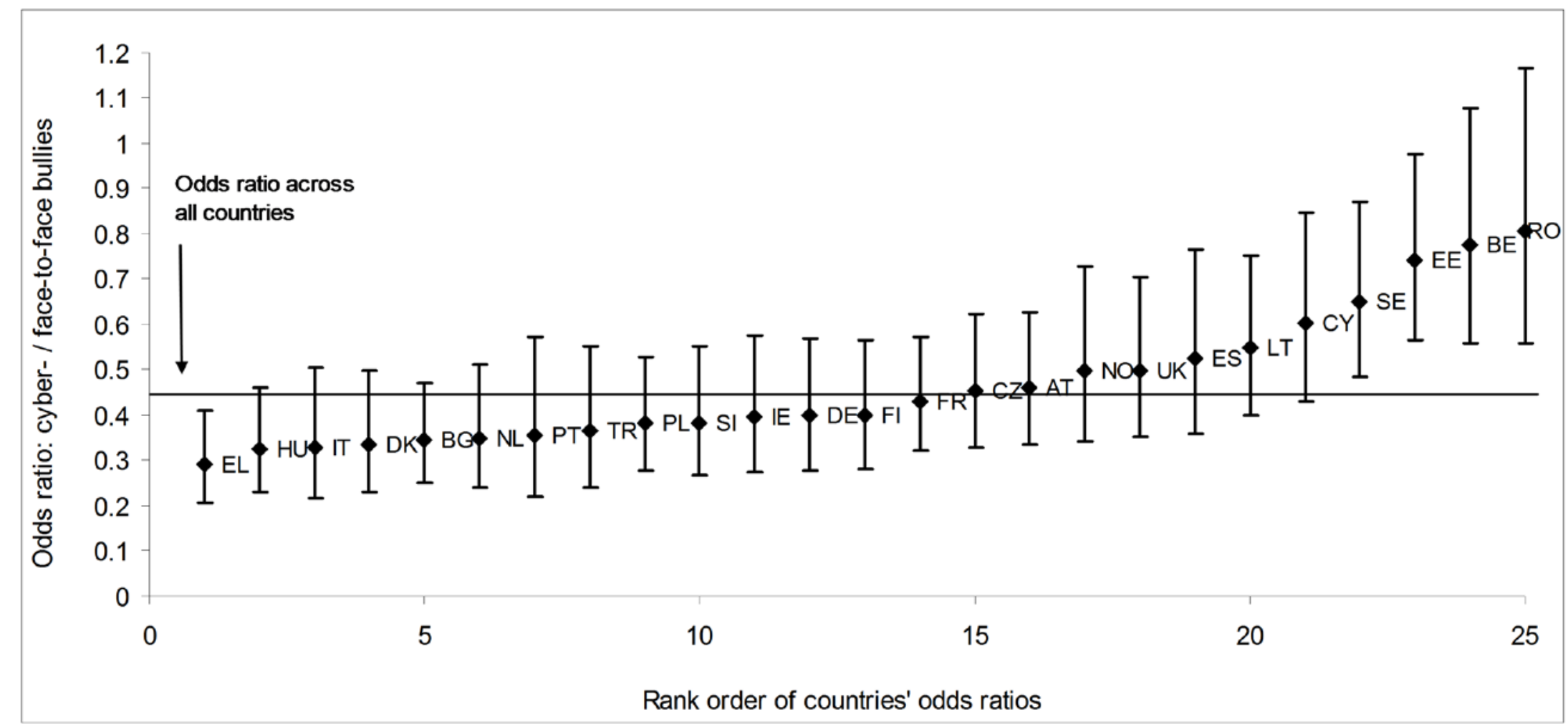


Figure 3

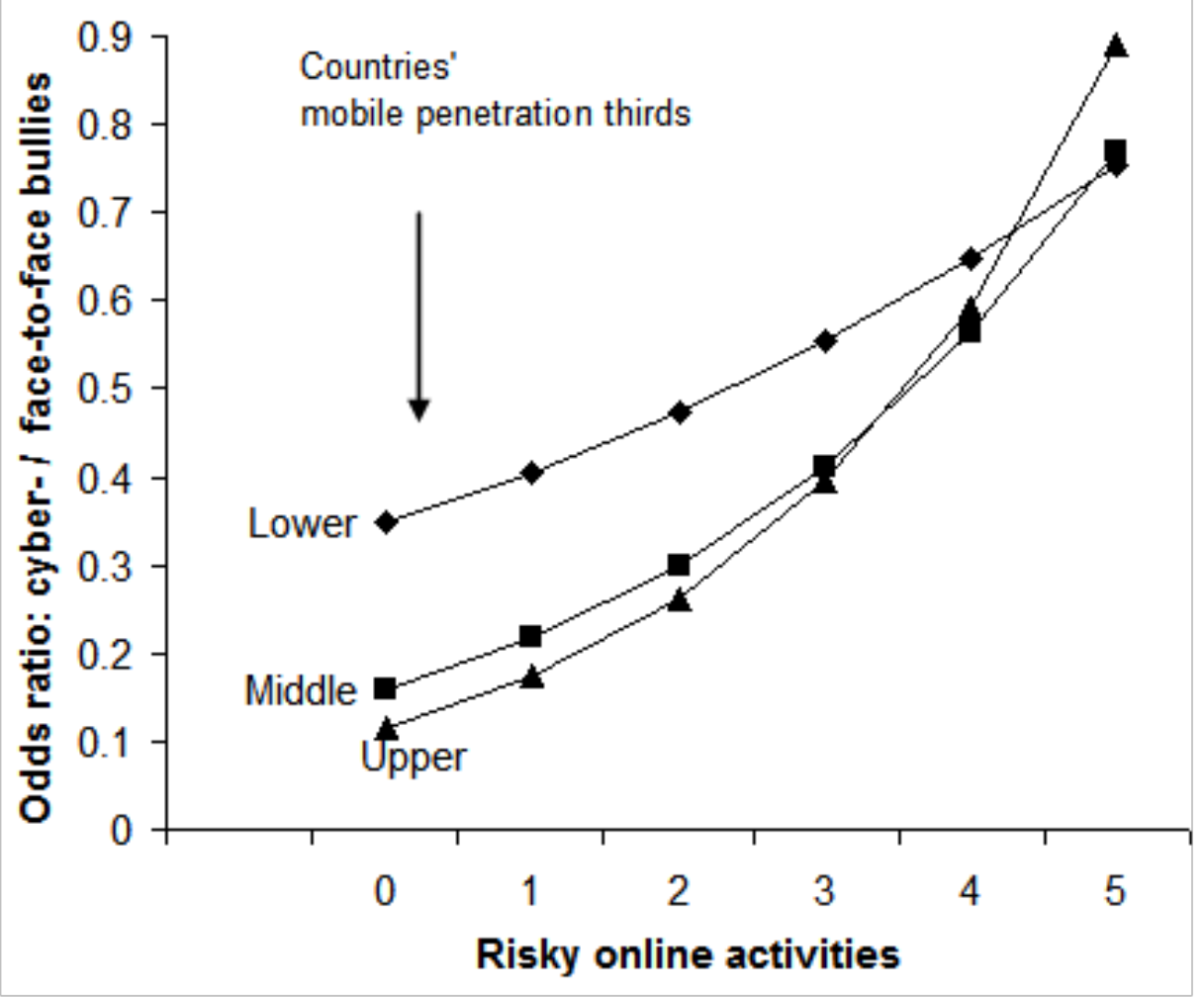


Figure captions

Figure 1. Percentage of cyberbullies amongst bullies by having a social networking site profile (SNS) and gender. Note. Error bars indicate 95\% confidence intervals.

Figure 2. Predicted odds ratios of cyberbullying versus face-to-face bullying by country. Note. Country abbreviations are as follows: Austria (AT), Belgium (BE), Bulgaria (BG), Cyprus (CY), the Czech Republic (CZ), Denmark (DK), Estonia (EE), Finland (FI), France (FR), Germany (DE), Greece (EL), Hungary (HU), Ireland (IE), Italy (IT), Lithuania (LT), the Netherlands (NL), Norway (NO), Poland (PL), Portugal (PT), Romania (RO), Slovenia (SI), Spain (ES), Sweden (SE), Turkey (TR) and the UK.

Figure 3. Predicted odds ratios for cyberbullying by risky online activities and countries' mobile penetration thirds. Note. Country thirds in mobile penetration are as follows - Lower: Austria, France, Turkey, Belgium, Slovenia, Norway, Spain, Romania, Poland; Middle: Sweden, Denmark, Estonia, Hungary, Ireland, Netherlands, UK; Upper: Cyprus, Germany, Finland, Czech Republic, Bulgaria, Portugal, Lithuania, Italy, Greece. 


\section{Acknowledgements}

This article draws on the work of the EU Kids Online network funded by the European

Commission (DG Information Society) Safer Internet plus Programme (project code

SIP-KEP-321803); see www.eukidsonline.net

We wish to thank Dr Lara Frumkin for her very helpful feedback. 